\title{
A Comparative Study of Social Comparison, Materialism, and Subjective Well-Being in the U. S., China, Croatia, and India
}

\author{
Jie G. McCardle \\ Georgia Southern University \\ Sandra S. Speck \\ Idaho State University
}

As the globalization of markets spreads Western media and consumerism across the world, it raises the question as to whether the arguments proposed by theories of social comparison and cultivation hold true in non-Western societies. In this study, we test the relationships between social comparison associated with television programming, materialism, and subjective well-being among college students from the United States, China, Croatia, and India. Structural equation modeling results reveal that the positive relationship between social comparison and materialism is universal. However, the mediating role of materialism between social comparison and subjective well-being is different between individualistic and collectivistic societies.

Keywords: Social Comparison Theory, Cultivation Theory, Television Programming, Materialism, Subjective Well-Being

\section{INTRODUCTION}

Scholars have long been interested in the effect of marketing efforts via television (TV) on the values and subjective well-being of consumers (Richins \& Dawson, 1992; Sirgy et al., 1998; Speck \& Roy, 2008). Research shows that TV programming and advertising play a significant role in cultivating materialistic values because the ideal images and messages projected by TV media provide a mechanism for upward comparison among their viewers (Richins \& Dawson, 1992). Consequently, the perceived gap between reality and the ideal lifestyle depicted on TV could inadvertently lead to a higher level of stress and dissatisfaction (Diener, Lucas, \& Oishi, 2002). Ample empirical evidence demonstrates that TV viewing can elevate materialistic values, which, in turn, leads to a decreased sense of well-being (Ahuvia, 2008b). The general conclusion in the Western consumer society is that, while it is in human nature to aspire for happiness, the belief that materialistic procession will make one happier inadvertently leads to reduced happiness and life satisfaction (Ahuvia, 2008b).

The globalization of the world economy has raised the standard of living in many developing countries. As a result of the spread of Western media across the world, the global market has seen the diffusion of the desire for Western consumer goods at a fast rate (Hine, 2002; Melendez, 1987). As economic development leads to the emergence of consumer culture (Ahuvia, 2002), two contrasting views seek to explain and predict the possible impact of consumer culture on societal values and 
subjective well-being. The convergence view argues that common values about economic activity and work-related behavior will lead to cultural synchronization (Hamelink, 1983; Levitt, 1993). In contrast, the divergence view emphasizes that national culture, not economic ideology or technological change, is the dominant force that will cause individuals to retain specific societal values (De Mooij \& Hofstede, 2002).

Research on subjective well-being has traditionally been conducted in the Western developed world with data primarily from Western European and North American nations. Despite the rise of research interest in developing countries in recent years, we know far less about the well-being of people from the Asian and other developing nations due to the underrepresentation of data from these regions (Tov \& $\mathrm{Au}$, 2013). As such, more cross-national studies in those representative samples are desirable. The pursuit of such studies will help scholars and practitioners reduce the discrepancies among macro-regions in our existing knowledge of well-being (Tov \& Au, 2013).

Two specific reasons prompted the present cross-national comparative study. First, consumerism is seen as coherent with individualistic cultures, in which people consider individual choices of a materialistic life as part of self-identity construction. Nevertheless, this argument is less compelling within collectivist cultures in which one's identity is largely shaped by one's social roles and relationships (Arnould \& Thompson, 2005). Second, the paradoxical impact of materialistic well-being on subjective well-being has been primarily established in societies that have experienced rapid growth of economic prosperity (Easterlin, 1995). For societies in which economic development is still in progress, materialistic values and consumerism might be still a fruitful pursuit for subjective well-being (Knight, Song, \& Gunatilaka, 2009). In other words, the assertation that materialism leads to lowered levels of life satisfaction may not hold in non-Western societies. In this regard, the global marketplace raises the question of how contextual differences could affect the outcomes of well-being research (Diener \& Oishi, 2000).

Television has become a major medium for entertainment and advertisement in many parts of the world in recent decades. Accordingly, scholars have embarked on the exploration of the influence of TV viewing on core values (e.g., materialism and religiosity) and subjective well-being (e.g., standard of living and life satisfaction) in different regions of the world (Ger \& Belk, 1996; Sirgy et al., 1998; Speck \& Roy, 2008). While the relationships between TV media, materialism, and life satisfaction have been generally established in consumer research, scholars remind us that "subjective well-being is a complex construct determined by a multitude of confluent factors" (Burroughs \& Rindfleisch, 2002, p. 349). Individual values, such as materialism, ought to be meaningfully studied and understood under their larger value system. As such, scholars call for more research on media and well-being in the global marketplace to fill in the gap in our existing knowledge body (Belk, 1985; Burroughs \& Rindfleisch, 2002; Richins \& Dawson, 1992).

In this study, we propose and test a multiple-step mediator model to explicitly examine the indirect mediating effect of materialism and material satisfaction between social comparison embedded in TV programming and life satisfaction. Studies show that societal levels of well-being are meaningfully related to macro-level social and economic conditions (Tov \& Au, 2013). While research conducted in the U. S. generally confirms the path between social comparison, materialism, and life satisfaction, we try to answer the question as to whether these relationships converge under the assimilation of material life or diverge due to cross-cultural differences. To the extent that materialistic value is subjective to value domains, we expect its impact on life satisfaction to differ depending on its respective societal values. Our study examines the paths between social comparison, materialism, material satisfaction, and life satisfaction among 882 college students from the U. S., China, Croatia, and India. These four countries represent a wide array of economic development and sociocultural backgrounds. Our findings reveal nuanced, complex relationships in our research model. On the one hand, the association between social comparison and materialism receives universal support; on the other hand, the mediating effects of materialism and material satisfaction exhibit a diverse pattern among the four countries.

This study contributes to the literature on materialism and well-being in several ways. First, we test social comparison behavior engendered by TV media directly. Past studies used TV viewership 
(measured by TV viewing time) as a proxy for social comparison. These studies found a low, albeit significant, effect of TV viewership on materialism. Our study examines the predictive power of social comparison embedded in TV programming while controlling for TV viewing time. Doing so allows us to detect the effect of social comparison on materialism unequivocally. Second, we test our hypotheses in four countries that represent a global coverage of social and economic contexts and, as such, contribute to our understanding of cross-cultural differences. Third, one empirical gap in previous studies is that the mediating path of materialism (i.e., the cultivation effect) between social comparison and life satisfaction was inferred via the direct association between segments of relationships. Our study explicitly tests the mediating hypothesis and, therefore, adds empirical rigor to this line of research.

\section{THEORY AND HYPOTHESES}

Subjective well-being refers to "a person's cognitive and affective evaluations of his or her life" (Diener et al., 2002, p. 63). Two primary cognitive elements of subjective well-being include perceived standard of living and life satisfaction. The perceived standard of living captures satisfaction with one's material income; in other words, material satisfaction. Life satisfaction refers to people's evaluation of their living conditions and is a key measure of subjective well-being. These two constructs have been validated as dimensions of subjective well-being by Nieboer, Lindenberg, Boomsma, and Bruggen (2005). Subjective well-being is an important source of information societies use to monitor the economic, social, and health conditions of populations and contributes to policy decisions (Krueger et al., 2009; Layard, 2006). It is the composite product of individual values and societal environment.

In the marketing literature, social comparison theory and cultivation theory provide explanations as to how social comparison and materialistic values can affect people's evaluation of their standard of living and life satisfaction. The cultivation theory points to a process in which social comparison embedded in media messages and images cultivates materialistic values. The social comparison theory posits that people, in general, are predisposed to compare their opinions and abilities with those of others (Festinger 1954), and in doing so, cultivating confidence - or the lack of - in their opinions and abilities. This

cultivation, in turn, leads to their life satisfaction. Figure 1 depicts our research model. 


\section{FIGURE 1}

\section{RESEARCH MODEL}

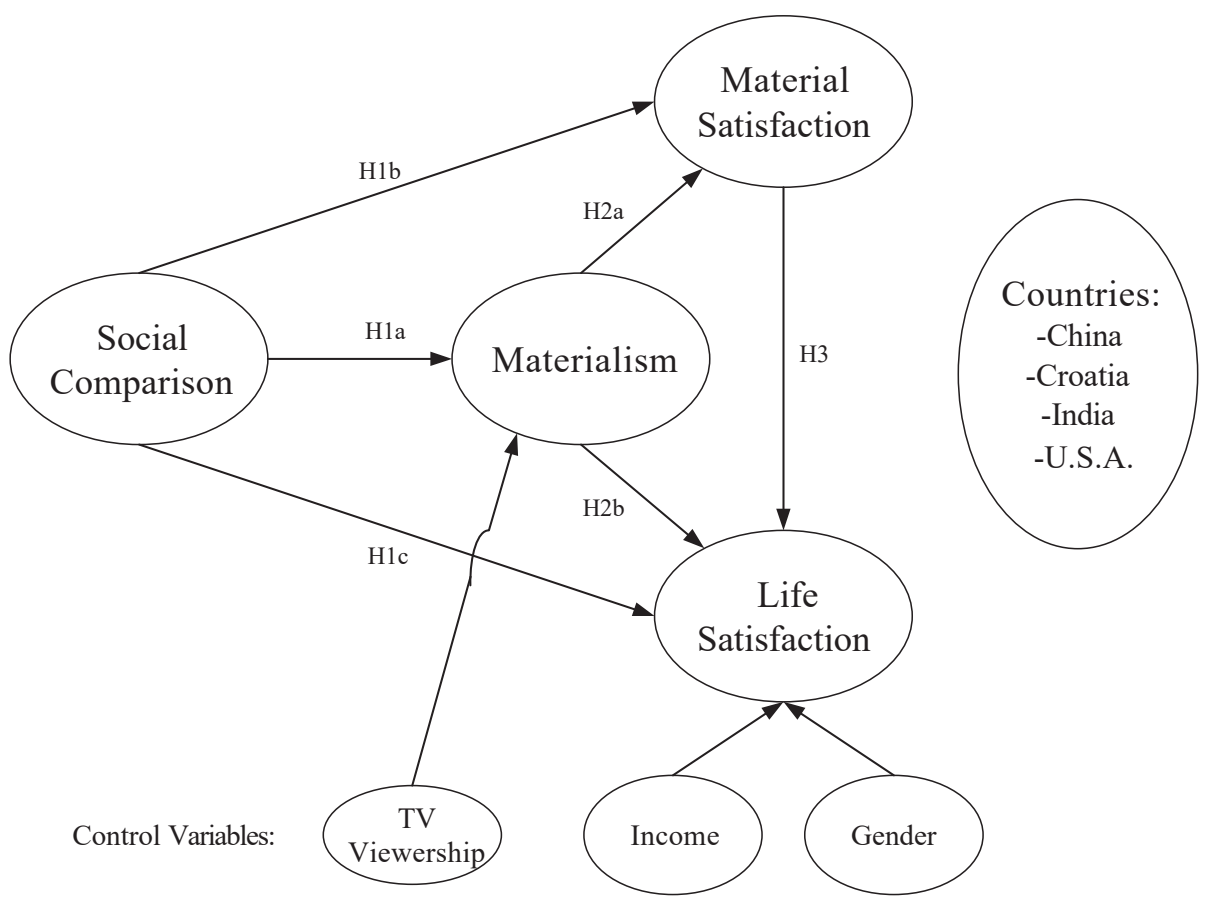

\section{Social Comparison, Television Programming, Materialism, and Well-Being}

According to Festinger (1954), individuals are equipped with the innate drive to evaluate their opinions and abilities by comparison with those of others. They learn about and assess themselves by comparison with other people and the information conveyed by the media. Social comparisons can take place both "downward," that is, with worse-off others, or "upward," that is, with better-off others. Media images depicted in TV programming and advertising contain valuable social image information, providing an upward reference of how we would like to see ourselves in life (Belk \& Bryce, 1986; Pollay, 1986a). Television informs consumers of what ought to be concerning their possessions, lifestyle, and status, and serves as an elevated standard of comparison. Its content influences the values held by consumers and, ultimately, that of society as a whole.

Richins (1991) conducted experiments to measure social comparison, regarding its act, standard, and impact on life satisfaction in the context of TV advertising. Her studies showed that consumers compared themselves with images depicted on TV that raised consumers' comparison standards. This process led to lowered satisfaction with the self. Yoon (1995) showed that consumers considered advertising an important source of social image information and found a significant relationship between advertising and materialism across African-American and Caucasian groups consisting of students and community adults. In this study, we will study the impact of social comparison on materialism and well-being by adopting measures from Richins's (1991) and Yoon's (1995) studies and test them beyond the context of American society.

In the modern era, television viewing has been by far the most time-consuming form of leisure in the United States (Kubey \& Csikszentmihalyi, 1990) and many other countries (Corneo, 2005; Kubey \& Csikszentmihalyi, 2004) with a broad range of audiences across different regions and education levels. Even those who cannot read or write can be influenced by the consumption-based lifestyles depicted in television advertising and programming (Melendez, 1987). The increasing access to television programming and advertising throughout the global market further escalates consumer aspirations. 
Television viewing has been directly linked to materialistic values. Richins and Dawson (1992, p. 308) conceptualize materialism as a value and define it as a "set of centrally held beliefs about the importance of possessions in one's life." When people place high values on materialism, such possession assumes a central place in their lives and is expected to provide the greatest sources of satisfaction and dissatisfaction. Subjective well-being research has long been intrigued by the paradoxical role of materialistic values play in life satisfaction. A common aspiration for the materialistic procession is that it can pave the way to the quest for psychological well-being (Tov \& Au, 2013).

A substantial body of research has been devoted to understanding the impact of materialism on consumers' well-being and quality of life (Sirgy, 1998). Compelling evidence shows that individuals who place high values on material procession exhibit diminished levels of life satisfaction (Richins \& Dawson, 1992). Studies consistently find that materialistic values exert a long-term negative effect for multiple domains of life satisfaction, including satisfaction with family, friends, fun, income, and life as a whole (Burroughs \& Rindfleisch, 2002; Diener et al., 2002; Sirgy, 1998; Speck \& Roy, 2008). As such, materialism is referred to as the "dark side" of consumer behavior (Hirschman, 1991).

Scholars posit that humans are consumers by nature who seek out media messages that reinforce their aspiration in life and find meaning in material objects (Richins, 1987). The extant literature has documented that TV programming and advertising exert a fundamental influence on consumer values and life satisfaction. Many studies support a robust effect of the quantity and consumerist content of television programming and advertising on consumers' attitudes toward materialism. This link is engendered by the act and process of social comparison induced in media viewing. Research has shown that heavy exposure to media and cultural imagery shapes a viewer's concept of reality (Gerbner, Gross, Morgan, Signorielli, \& Shanahan, 2002).

Consequently, spending habits displayed in TV media lead to anxieties and stress in those who do not have the economic means to participate in opulent consumption (Richins, 1991). Materialism is considered to be an inevitable product of the modern consumer culture in which earning, shopping, and owning occupy central parts of people's lives. TV media has long been criticized for promoting materialism (Gerbner et al., 2002; Pollay, 1986a). In contrast, consumers low in materialism are more satisfied with their socioeconomic status than are those who place a higher value on material things (Richins \& Dawson, 1992).

Furthermore, one's material satisfaction, or perceived socioeconomic status, is an important life domain that is likely to influence life satisfaction positively (Leelanuithanit, Day, \& Walters, 1991). For example, in the United States, Fernandez and Kulik (1981) find that people with higher socioeconomic status are more highly satisfied with their lives than those with lower income in the same neighborhoods. Therefore, we propose the following hypotheses:

Hypothesis 1a: Social comparison is positively associated with materialism.

Hypothesis 1b: Social comparison is negatively associated with material satisfaction.

Hypothesis 1c: Social comparison is negatively associated with life satisfaction.

Hypothesis 2a: Materialism is negatively associated with material satisfaction.

Hypothesis 2b: Materialism is negatively associated with life satisfaction.

Hypothesis 3: Material satisfaction is positively associated with life satisfaction.

\section{The Mediating Effect of Materialism}

Cultivation theory holds that personal values are cultivated over a long period of time in one's upbringing, and it is the cumulative effect of repeated exposure to the mass media that gradually influences people's value priorities and work views as adults (Besley, 2008). Television media enhances 
materialistic values, which adversely impact life satisfaction because television functions as a social tool of acculturation (Belk, 1985; Burroughs \& Rindfleisch, 2002; Gerbner et al., 2002). In the commercial world, marketers and advertisers have long recognized the potential for programming and advertising content to influence television viewers. Indeed, television programming content is closely linked to the goals of marketers (Kubey \& Csikszentmihalyi, 2002). Advertisers, in particular, pay close attention as to how the values expressed in advertisements will interact with those presented by the program content, ensuring that their respective values are consistent (Pollay, 1986b; Speck \& Roy, 2008). Consequentially, increased exposure to mass media fuels consumption and materialism.

Television cultivates materialism because it can over portray affluence relative to its real-world incidence (Lichter, Lichter, \& Rothman, 1994). Greater quantities of television viewing have been shown to positively correlate with estimates of the prevalence of expensive products (O'Guinn \& Shrum, 1997) and higher levels of materialism (Burroughs \& Rindfleisch, 2002). Consumption occupies a mass leisure activity and a source of happiness in consumer societies. The content of TV program affects not only the level of materialism in a culture, but also consumers' perspectives on their general socioeconomic status, and creates satisfaction or dissatisfaction with their lives. The literature on marketing and advertising suggests that television is a primary vehicle companies use for brand building and that the messages they deliver to the receivers tend to be consistent and coherent (Draganska, Hartmann, \& Stanglein, 2013). According to the rationale of social comparison theory, individuals develop their perceptions by comparing the materialistic aspect of their lives to the commercial information depicted on television. Therefore, television media can exert a negative influence on material satisfaction.

The increased exposure to mass media not only can fuel consumption and materialism but can also have an adverse consequence on the overall life satisfaction through materialistic tendencies (Kubey \& Csikszentmihalyi, 1990). Television viewing tends to reduce life satisfaction because it can foster a more extrinsic focus on material values at the expense of intrinsic values such as friendship, spirituality, and societal contribution (Shrum, Burroughs, \& Rindfleisch, 2005).

Paradoxically, the combination of an intrinsic desire for happiness and the belief that money leads to happiness results in reduced subjective well-being. Theories of materialism suggest that less materialistic value systems are healthier for human beings than highly materialistic value systems. People who place high values on material possession tend to suffer disproportionately from a host of maladies, including anxiety, depression, negative emotions, addiction, behavior disorders, low levels of meaningfulness, and low levels of life satisfaction (Ahuvia, 2008a). Strong evidence shows that cultivation of materialism leads to a less satisfied, and less happy, life.

While studies generally support cultivation theory suggesting that media contributes to terminal materialism and leads to diminished life satisfaction (Sirgy et al., 1998; Speck \& Roy, 2008), some scholars have contemplated the rationale that TV viewing reflects cultural values, such as materialism, rather than creates such values. For example, (Richins, 1991, p. 2) described that "materialists are more externally oriented than others, more self-conscious and self-monitoring. Social comparison is an important mechanism for evaluating status." Given this theoretical contradiction, Sirgy et al. (2012) and (Speck \& Roy, 2008) considered a reverse path from materialism to social comparison and tested this path empirically. Their results provided strong support for the cultivation hypothesis. This research evidence provides us with the confidence to treat social comparison as an exogenous variable for materialism.

In addition, as discussed above, material satisfaction is an important domain of life that contributions to life satisfaction. Therefore, we also expect a pathway from materialism to material satisfaction and life satisfaction.

Hypothesis 4a: Materialism negatively mediates the relationship between social comparison and material satisfaction.

Hypothesis 4b: Materialism negatively mediates the relationship between social comparison and life satisfaction. 
Hypothesis 5: Material satisfaction positively mediates the relationship between social comparison and life satisfaction.

\section{Social Comparison, Materialism, and Well-Being in the Global Market}

Given the widespread nature of materialistic messages in the global media, material values are expected to instigate value conflicts or transition for individuals in many societies. Scholars recognize that, while global economies continue to converge in the technological and material realm, cultures continue to diverge as a behavioral mechanism, and regional identities are surprisingly durable (Huntington, 2000). A limited number of studies tested social comparison theory and cultivation theory in different countries and regions and found support over the segments of the relationships between the quantity of TV viewing, materialism, and subjective well-being.

Empirically, while the negative association between materialism and well-being has been studied and supported in the U. S. sample, cross-cultural study of materialism suggests great variations. For example, Dawson and Bamossy (1991) found that the negative relationship between materialism and well-being was only significant for the American sample but not for the Dutch. Ger and Belk (1996) showed materialistic values were complicated, not lining up along economic wealth or cultural dimensions. Ger and Belk (1996, p. 63) suggested that, while Americans were "apt to see materialism as excessive and as a weakness," Romanians and Turks "see materialism as an empowering and self-enhancing expression of control and freedom." Speck and Roy (2008) extended the research of cultivation theory to 13 counties from five different regions worldwide. Their analysis showed that, while the negative effect of the quantity of television viewing on materialism and life satisfaction in the global audience for most regions examined was widespread, the cultivation theory received only inconsistent support.

Regarding the impact of social comparison on materialism, Chan and Prendergast (2008) demonstrated that social comparison led to materialism among young Chinese. Chung and Mallery (1999) suggested that collectivists were more likely to make an upward comparison that could lead to lower life satisfaction. These studies strongly suggest that materialism might be a socially-constructed manifestation that varies based on the sociocultural context of a particular society.

Therefore, a close look at cross-national studies revealed that the relationships between TV media, materialism, and life satisfaction are complex, diverse, and vary from sample to sample. This situation is understandable, given that values are subjective to the influence of the sociocultural context and other individual values. The conditions that foster materialistic values and consumption behavior are expected to be different from the U. S. than in many other parts of the world. Marketing literature suggests that two attributes define modern Western consumer societies. One is the prevalence of the marketplace in people's daily lives. Individuals spend a significant amount of their resources, such as time, money, and energy, on acquiring, spending, and consuming materialistic wealth (Campbell, 1987). The other one is the central role of consumption choices take in constructing one's self-identity (Ahuvia, 2002, 2008b). In this study, we suggest that national cultural differences in individualism/collectivism can alter the relationships proposed by theories of social comparison and cultivation.

Individualism/collectivism is a cultural characteristic that represents a preference for a tightly-knit framework in society. It affects the degree to which individuals express pride, loyalty, and cohesiveness in their organizations and societies (Hofstede, 2003). In high individualistic societies, the emphasis of self-identity is placed on individual initiative, self-sufficiency, and individual accomplishment. Personal needs and attitudes emerge as important determinants of social behavior. The centrality of consumer choices in helping people shape their sense of identity is consistent with individualistic values. In individualistic societies, the importance of consumption choices in achieving the individual's sense of identity is heightened in consumer behavior. In individualistic consumer societies, identity is much less assigned than it is achieved (Baumeister, 1991). The pursuit of personal happiness is seen as a value to be pursued with all one's might. Consumption becomes a proxy of one's ability to actualize one's authentic self. As such, consumer choices are naturally seen as an antecedent of personal happiness.

In collectivistic societies, people define personal identity based on their relatedness with their group and to a large degree (Hofstede, 2003). In collectivistic, traditional, less consumer-oriented societies, 
much of one's identity is largely a function of the existing circumstances, such as family and social class, one is born into (Slater \& Tonkiss, 2013). One's identity draws a large input from one's social roles and relationships, and pursuit of personal happiness is often relegated to a secondary concern (Markus \& Kitayama, 1991). Ahuvia (2002) posits that the pursuit of happiness becomes a significant personal mission and a cultural fixation when people go through the transition from assigned to achieved identities. This condition implies that the relationship between materialism and life satisfaction does not necessarily hold in non-individualistic, less consumer-oriented societies. Richins (1991) study of social comparison and materialism is described in the context of American media. As capitalism spread throughout the world, it brought consumerism into many more aspects of people's lives (Kasser \& Kanner, 2004). Therefore, we will test whether theories of social comparison and cultivation apply in different cultural contexts.

Research Question: What is the role of materialism in the relationship between social comparison and subjective well-being (material satisfaction and life satisfaction) in individualistic vs. collectivistic societies?

\section{METHODS}

\section{Sample and Data}

Marketing professors from different counties were recruited via professional networking (email and personal contact) to assist in the data collection between 2011 and 2012. A purposive sampling approach was used to recruit professors in order to get a reasonably representative sample from around the globe (Douglas \& Craig, 2006). College students were targeted for participation due to several advantages associated with their demographic attributes. First, these students could provide insights into our research inquiry because they were more likely than the general population in their respective countries to have access to television. Second, the homogeneity of the sample satisfied the comparability criterion and allowed the test of the external validity of the theory in cross-cultural research (Mullen, 1995). Third, the participating faculty confirmed that respondents had a good comprehension of English, which allowed us to provide all questionnaires in English, and, thus, mitigating potential measurement equivalence concerns.

This procedure generated a useful sample of 994 responses. After deleting cases with missing values, the final sample consists of 882 participants from four counties: China (308), Croatia (227), India (87), and the U.S.A. (260). Table 1 lists the sample characteristics, including the number of participants, gender ratio, index of individualism and collectivism reported by the Hofstede (2003) study, as well as the index of country economic development (national income and purchasing power parity). As seen in the table, the U. S. ranks much higher on individualism and economic development than the other three countries do.

TABLE 1

DEMOGRAPHIC PROFILE OF SAMPLE GROUPS

\begin{tabular}{|l|l|l|l|l|l|l|}
\hline Country & $\begin{array}{l}\text { Sample Size } \\
(\mathrm{N})\end{array}$ & $\begin{array}{l}\text { Gender } \\
\mathrm{M} / \mathrm{F}\end{array}$ & $\begin{array}{l}\text { I/C* } \\
\text { Index }\end{array}$ & $\begin{array}{l}\text { HDI } \\
(\text { Rank })\end{array}$ & $\begin{array}{l}\text { GDP per Capita } \\
(\mathrm{US} \$, 2013)\end{array}$ & $\begin{array}{l}\text { GDP at PPP** } \\
(\mathrm{US} \$, 2013)\end{array}$ \\
\hline China & 308 & $148 / 160$ & 20 & $0.699(101)$ & 7,080 & 12,360 \\
\hline Croatia & 227 & $51 / 176$ & 33 & $0.805(47)$ & 13,650 & 21,780 \\
\hline India & 87 & $66 / 21$ & 48 & $0.554(136)$ & 1,450 & 5,250 \\
\hline U.S.A. & 260 & $142 / 118$ & 91 & $0.937(3)$ & 52,780 & 52,780 \\
\hline Total & 882 & $407 / 475$ & & & & \\
\hline
\end{tabular}

*I/C: Individualism/Collectivism, **PPP: Purchase Power Parity, Source: World Bank, 2014 


\section{Measures}

Following the procedures recommended by Gerbing and Anderson (1988), we relied mostly on established multi-item scales previously published in the literature. A series of confirmatory factor analyses (CFAs) was conducted to establish the validity and reliability of the constructs in our sample prior to hypothesis tests. Appendix A reports the measures used for each construct.

Social comparison is a seven-item measure adopted from Richins (1991) and Yoon (1995) studies. It captures the comparison individuals make as consumers with the models, imagines, and messages projected in TV programming. Materialism is conceptualized as a value in this study and measured accordingly. We adopted Richins and Dawson (1992) measure that is anchored on acquisition centrality, possession-defined success, and acquisition as the pursuit of happiness. The materialism measure has been shown to display relatively lower validity and reliability in the literature due to its multifaceted and implicit nature. Measurement items have not been consistent across different studies (Speck \& Roy, 2008). To maintain an acceptable validity across sample groups from different countries, we used a simplified three-item measure that taps into the three aspects of materialism. Material satisfaction is measured by a four-item scale with which respondents rated their satisfaction with their standards of living on a scale of seven response categories (Sirgy et al., 1998; Speck \& Roy, 2008). Life satisfaction is measured by a five-item scale with which respondents rated their satisfaction with their lives on a scale of seven response categories (Meadow, Mentzer, Rahtz, \& Sirgy, 1992). The measure is based on the theory that life satisfaction is a function of a comparison between perceived life accomplishments and a set of evoked standards. The standards are classified according to their referent sources (e.g., the life accomplishments of relatives, friends, associates, and the average person in a similar position, past experience, self-concept of strengths and weaknesses) and different forms of expectations.

\section{Control Variables}

We included a number of control variables that have been reported to affect materialism and wellbeing. These variables included television viewership for materialism, and family income and gender for life satisfaction.

Television viewership is a three-item scale that measures the frequency and quantity of television viewing as in previous studies (Sirgy et al., 1998; Speck \& Roy, 2008). For income level, respondents ranked their family income in their respective countries in one of the three levels: above average $(\mathrm{N}=$ $209,23.6 \%)$, average $(\mathrm{N}=448,50.8 \%)$, and below average $(225,25.6 \%)$. Dummy variables were created for analysis with the "below average" group used as the comparison group. For gender, a dummy variable (one for female and zero for male) was created for this variable, and the male group was used as the comparison group. The male-to-female ratio in the sample was slightly skewed toward female $(\mathrm{N}=487$, $55.2 \%)$ vs. male $(\mathrm{N}=395,44.8 \%)$. The sample domain, that is, college students, ensured that the age distribution of the participants is rather invariant. Among the 882 data points, the age of $804(91.16 \%)$ participants ranged between 18 to 29 years old. As such, we did not include age as a control variable due to its homogeneity. Table 2 reports the means, standard deviations, and bivariate correlations of our key constructs. 
TABLE 2

DESCRIPTIVE STATISTICS AND BIVARIATE CORRELATIONS

\begin{tabular}{|l|l|l|l|l|l|l|}
\hline & Mean & S. D & SC & MAT & MS & LS \\
\hline SC & 2.73 & 1.09 & & & & \\
\hline MAT & 2.31 & 0.74 & $.408^{* *}$ & & & \\
\hline MS & 2.04 & 0.56 & $.301^{* *}$ & $-.079^{*}$ & & \\
\hline LS & 2.88 & 0.65 & $-.195^{* *}$ & $-.267^{* *}$ & $.229^{* *}$ & \\
\hline TVView & 2.08 & 0.59 & $.144^{* *}$ & $.158^{* *}$ & $-.152^{* *}$ & -0.03 \\
\hline
\end{tabular}

SC-Social Comparison; LS-Life Satisfaction; MAT-Materialism; MS-Material Satisfaction; TV-TV Viewership, see Appendix A for an explanation of the variables.

$* \mathrm{p}<.05, * * \mathrm{p}<.01$

\section{Measurement Model}

We used the two-step approach for SEM analysis following the suggestions of Anderson and Gerbing (1988). Data were analyzed using the AMOS 24 software package. CFAs were conducted to assess the overall model fit and construct validity. The Goodness-of-fit statistics suggested that the data fit the overall model well: $\mathrm{CMIN} / \mathrm{DF}=859.12 / 275=3.13, \mathrm{CFI}=.96, \mathrm{SRMR}=.04, \mathrm{RMSEA}=.05, \mathrm{PCLOSE}=$ 98. Table 3 reports the validity and reliability results.

For convergent validity, each indicator's estimated coefficient loaded significantly $(p<.001)$ on its underlying construct; and the Average Variance Extracted (AVEs) for social comparison (.53), materialism (.47), material satisfaction (.57), life satisfaction (.58), and TV viewership (.48) were either above or close to the suggested cutoff score of .50 (O'Leary-Kelly \& Vokurka, 1998). Past studies noted inconsistent validity and reliability in measuring materialism due to its multifaceted attributes (Roberts, Manolis, \& Tanner Jr, 2003; Sirgy et al., 1998; Speck \& Roy, 2008). TV viewership taps into different TV viewing schedules (on weekends, every day, hardly [reverse coded]) and, as such, its convergent validity was of less concern.

Results confirmed discriminant validity for all constructs. As seen in table 3, the Maximum Shared Variance (MSV) values were less than the AVE values; and the AVE values were above the Average Shared Variances (ASV) values. Also, the square root of AVE was larger than the inter-construct correlations in all instances. Composite reliabilities (C.R.) were calculated to assess the internal reliability of scales; all were well above acceptable levels of 0.7 (Fornell \& Larcker, 1981).

College students completed the survey in English. We also conducted a multi-group confirmatory factor analysis for the sample from each country to check for pooling bias and validate the measurement model $(\mathrm{CMIN} / \mathrm{DF}=1.55, \mathrm{SRMR}=.06, \mathrm{CFI}=.94, \mathrm{RMSEA}=.03, \mathrm{PCLOSE}=1.0)$. This analysis provided evidence for measurement invariance, as recommended by Mullen (1995).

TABLE 3

MEASUREMENT VALIDITY AND RELIABILITY

\begin{tabular}{|l|l|l|l|l|l|l|l|l|l|}
\hline & CR & AVE & MSV & ASV & SC & LS & MAT & MS & TV \\
\hline SC & 0.89 & 0.53 & 0.12 & 0.06 & 0.73 & & & & \\
\hline LS & 0.87 & 0.58 & 0.05 & 0.02 & -0.17 & 0.76 & & & \\
\hline MAT & 0.72 & 0.47 & 0.12 & 0.04 & 0.35 & -0.22 & 0.69 & & \\
\hline MS & 0.84 & 0.57 & 0.07 & 0.03 & 0.26 & 0.20 & -0.07 & 0.75 & \\
\hline TV & 0.73 & 0.48 & 0.02 & 0.01 & 0.12 & -0.02 & 0.13 & -0.13 & 0.69 \\
\hline
\end{tabular}




\section{Structural Model}

We used SEM to test the hypotheses proposed in our model. SEM allows simultaneous testing of the hypothesized relationships while accounting for all other paths in the model. It also has the advantage of reducing the chances of Type I errors and exhibiting greater statistical power for multi-group analysis when the sample sizes are not equal (James, Mulaik, \& Brett, 2006). To detect country differences, we ran simultaneous SEM models based on the pooled and multi-country samples.

For mediation analysis, recent literature suggests that a bootstrap test of the indirect effect is the only appropriate method to establish mediation for a multiple-step multiple mediator model, given the nonnormal sampling distribution of the product of the two indirect pathways used to estimate the indirect mediation effect (Rungtusanatham, Ng, Zhao, \& Lee, 2008; Zhao, Lynch, \& Chen, 2010). We used biascorrected bootstrap methods to test the mediating effect (Preacher \& Hayes, 2008). Five thousand resamples with replacement were used to empirically represent the sampling distribution of the indirect effects. This method determined the product of the constituent mediation pathways by estimating the indirect effect in the population sampled and thereby generate a 95 percent confidence interval. According to Zhao et al. (2010, p. 204), "to establish mediation, all that matters is that the indirect effect is significant." To determine this, we ran two separate SEM mediation models. In the first (partial) model, we tested the mediating effect of materialism between social comparison and life satisfaction without material satisfaction (hypothesis 4b). The second (full) SEM model includes both materialism and material satisfaction as mediators. Table 4 summarizes the key results of the SEM analyses for country comparison. Details of the analysis results for each sample group (pooled and country specific samples) are provided in Appendix B. The results for hypothesis $4 \mathrm{~b}$ are based on the partial model. All other results reported in Table 4 and Appendix B are based on the full model.

Hypotheses 1a, 1b, and 1c predict the direct effect of social comparison on materialism, material satisfaction, and life satisfaction, respectively. Results provide strong and universal support for these hypotheses. The only exception is that hypothesis 1c (the association between social comparison and life satisfaction) is not significant in the Chinese sample. An interesting twist of our results is that the impact of social comparison on material satisfaction is positive in all four countries. This finding is in the opposite direction of hypothesis $1 \mathrm{~b}$ that is proposed based on previous research findings (Sirgy et al., 1998). Hypothesis 1b implies that television program provides references for upward comparison. Alternatively, it is possible that the need for self-confirmation can motivate people to use the information depicted on television for downward, or lateral comparison, a choice that can lead to satisfaction (Tiggemann \& Polivy, 2010). We suggest more empirical evidence is needed to test the specific social comparison people make and its effect on their satisfaction with the standard of living. Overall, the impact of social comparison on materialism and subjective well-being receives strong and universal support in our study.

Hypothesis $2 \mathrm{a}$ that predicts the direct effect of materialism on material satisfaction is supported in the U. S., Chinese, and Croatia samples, but not in the India sample. Hypothesis $2 b$ that predicts the direct effect of materialism on life satisfaction is supported in the U. S. sample only. This finding confirms our suggestion that materialism might be a socially-constructed manifestation that varies based on the specific sociocultural context.

Hypothesis 3 predicts the direct effect of material satisfaction on life satisfaction and receives strong, universal support in all four countries. This finding is consistent with the traditional life satisfaction research that shows life satisfaction moves up and down along the variation of living conditions.

Regarding the cultivation hypothesis, our mediating analyses present country-specific differences. Hypothesis $4 \mathrm{a}$ is mostly supported as materialism is a significant, partial mediator between social comparison and material satisfaction in the U. S., China, and Croatia, with the exception of India. This mediation path is competitive. With a competitive mediation, the mediated effect and direct effect point in opposite directions. A competitive mediation pattern suggests that the mediator is consistent with the hypothesized theoretical framework, but it is likely that another mediator exists in the "direct" path (Zhao et al., 2010). 
Hypothesis $4 \mathrm{~b}$ is supported in the U. S. and Croatia that show a significant, partial mediation between social comparison and life satisfaction. But this mediating path is not significant in China and India. The significant mediation effect is complementary (Zhao et al., 2010). A complementary mediation occurs when the mediated effect and direct effect both exist and point in the same direction. Similar to a competitive mediation, a complementary mediation pattern suggests that the mediator is consistent with the hypothesized theoretical framework, although another mediator is likely to exist (Zhao et al., 2010).

The mediating effect of materialism between social comparison and life satisfaction is significant in the U. S. and China, but not in Croatia and India. Furthermore, this path exhibits partial (complementary) mediation in the U. S. and full mediation in China. A full mediation implies "mediator identified consistent with the hypothesized theoretical framework" (Zhou et al., 2010, p. 200).

In sum, our findings in the U. S. sample are consistent with those in the previous studies, and therefore provide further empirical support for theories of social comparison and cultivation. Meanwhile, our multi-country analyses reveal much more nuanced relationships between the variables in our model. Our findings show that, although these theoretical arguments can be validated in an individualistic culture, they do not always hold true in a collectivistic culture.

TABLE 4 HYPOTHESES TEST RESULTS SUMMARY FOR COUNTRY COMPARISON*

\begin{tabular}{|c|c|c|c|c|c|c|c|c|c|}
\hline & & \multicolumn{2}{|l|}{ USA } & \multicolumn{2}{|l|}{ China } & \multicolumn{2}{|l|}{ Croatia } & \multicolumn{2}{|l|}{ India } \\
\hline $\begin{array}{l}\text { Structural } \\
\text { Path }\end{array}$ & & $\underline{\text { Effect }}$ & $\begin{array}{l}\text { Sup- } \\
\text { ported? }\end{array}$ & $\underline{\text { Effect }}$ & $\begin{array}{l}\text { Sup- } \\
\text { ported? }\end{array}$ & $\underline{\text { Effect }}$ & $\begin{array}{l}\text { Sup- } \\
\text { ported? }\end{array}$ & $\underline{\text { Effect }}$ & $\begin{array}{l}\text { Sup- } \\
\text { ported? }\end{array}$ \\
\hline$\overline{\mathrm{SC}} \rightarrow \mathrm{MAT}$ & H1a & $.43 * *$ & Yes & $.25 * *$ & Yes & $.47 * *$ & Yes & $.42 * *$ & Yes \\
\hline $\mathrm{SC} \rightarrow \mathrm{MS}$ & H1b & $.24 * *$ & Yes & $.46 * *$ & Yes & $.33 * *$ & Yes & $.25 * *$ & Yes \\
\hline $\mathrm{SC} \rightarrow \mathrm{LS}$ & $\mathrm{H} 1 \mathrm{c}$ & $-.18 * *$ & Yes & .05 & No & $-.22 * *$ & Yes & $-.19+$ & Yes \\
\hline $\mathrm{MAT} \rightarrow \mathrm{MS}$ & $\mathrm{H} 2 \mathrm{a}$ & $-.29 * *$ & Yes & $-.28 * *$ & Yes & $-.22 * *$ & Yes & -.07 & No \\
\hline MAT $\rightarrow$ LS & $\mathrm{H} 2 \mathrm{~b}$ & $-.27 * *$ & Yes & .03 & No & -.07 & No & -.05 & No \\
\hline $\mathrm{MS} \rightarrow \mathrm{LS}$ & $\mathrm{H} 3$ & $.31 * *$ & Yes & $.47 * *$ & Yes & $.30 * *$ & Yes & .25 & Yes \\
\hline $\begin{array}{l}\mathrm{SC} \rightarrow \mathrm{MAT} \\
\rightarrow \mathrm{MS}\end{array}$ & $\mathrm{H} 4 \mathrm{a}$ & $-.13 * *$ & $\begin{array}{l}\text { Com- } \\
\text { petitive }\end{array}$ & $-.07 * *$ & $\begin{array}{l}\text { Com- } \\
\text { petitive }\end{array}$ & $-.10 * *$ & $\begin{array}{l}\text { Com- } \\
\text { petitive }\end{array}$ & -.03 & No \\
\hline $\begin{array}{l}\mathrm{SC} \rightarrow \mathrm{MAT} \\
\rightarrow \mathrm{LS}\end{array}$ & $\mathrm{H} 4 \mathrm{~b}$ & $-.16 * *$ & $\begin{array}{l}\text { Comple- } \\
\text { mentary }\end{array}$ & -.02 & No & $-.06+$ & $\begin{array}{l}\text { Comple- } \\
\text { mentary }\end{array}$ & -.03 & No \\
\hline $\begin{array}{l}\mathrm{SC} \rightarrow \mathrm{MS} \rightarrow \\
\mathrm{LS}\end{array}$ & H5 & $-.08 *$ & $\begin{array}{l}\text { Comple- } \\
\text { mentary }\end{array}$ & $.19 * *$ & $\begin{array}{l}\text { Full } \\
\text { Media- } \\
\text { tion }\end{array}$ & .04 & No & .04 & No \\
\hline
\end{tabular}

*Detailed SEM results for the pooled sample and each country are reported in Appendix B. ${ }^{+} \mathrm{p}<.10, * \mathrm{p}<.05, * * \mathrm{p}<.01$.

The control variables also reveal some interesting findings. TV viewership shows a positive influence on materialism in the U. S. $(\beta=.14 ; p<.10)$, China $(\beta=.16 ; p<.10)$, Croatia $(\beta=.25 ; p<.01)$. However, this effect is negative in India $(\beta=-.28 ; p<.05)$. Parsing out the effect of TV viewership on materialism further confirms the rigor of the findings over the effect of social comparison in our model. Female participants report a higher level of life satisfaction in China $(\beta=.14 ; \mathrm{p}<.05)$ and Croatia $(\beta=$ $.28 ; \mathrm{p}<.01)$, but a lower level of life satisfaction in India $(\beta=.30 ; \mathrm{p}<.01)$, compared to the male participants. Gender effect is not significant in the U. S. sample. Family income is not related to life satisfaction in any of the four countries. 


\section{DISCUSSION}

\section{Contribution}

This study is motivated by the paradigm that "globalization lies at the heart of modern culture; cultural practices lie at the heart of globalization" (Tomlinson, 1999, p. 1). The debate over the impact of globalization on the cultural change proposed convergent and divergent perspectives. The globalization of media has been instrumental in expanding the marketplace for Western products. Along with economic progress, societies shift from "traditional values" to "secular-rational" values, and from "survival values" to "well-being values" (Inglehart, 2006). In our introduction, we reviewed that two contrasting views have been proposed to explain and predict the trend of the shift of social values associated with the globalization of the market. The convergence view argues that, as countries liberalize their markets, develop institutions, adopt modern technology, and achieve industrialization, business behavior becomes similar because people will embrace common values about economic activity and work-related behavior. For example, media theorist Hamelink (1983) believed that the rapid process of cultural synchronization would greatly reduce the variety of the world's cultural systems. Similarly, Levitt (1993) proposed that, as globalization transformed the world into a "homo-cultural" marketplace, all customers would share the same values and could be persuaded by similar advertising appeals, irrespective of the traditional culture to which they belong (Speck \& Roy, 2008).

In contrast, the divergence view emphasizes that national culture, not economic ideology or technological growth, is the dominant force in shaping the values, beliefs, and attitudes of consumers. For example, the globalization of media has been instrumental in the spread of Western values and ideas, such as liberal democracy, materialism, and equal rights for women, all over the world. Nevertheless, these changes inadvertently created heightened tensions between many traditional societies and Western societies. According to the divergent view, globalization is not about convergence to best practices, but rather about leveraging difference in an increasingly borderless world to gain differentiated positions and advantages (De Mooij \& Hofstede, 2002).

Our findings reveal both convergent and divergent elements in our quest to understand the role that television media plays in people's lives. On the one hand, we show that social comparison engendered by TV program contributes to materialism across both individualistic and collectivistic cultures and different levels of economic conditions. As well, material satisfaction is significantly associated with life satisfaction in all four countries. Furthermore, the paths from social comparison, channeled by materialism and material satisfaction exhibits national distinctions. There are variations in the evidence that support the cultivation hypothesis in our sample. While our study adds empirical support for cultivation theory in different countries, these relationships are complex and beget further investigation.

Given the globalization of media, it is critical for scholars and practitioners to decipher the complexity of the interrelationships between economic behavior, social values, and life satisfaction. Our study makes a valuable contribution to international research of marketing, media, and well-being by testing theories of social comparison and cultivation in a global context.

\section{Limitation}

Cultivation theory depicts that the cumulative effect of repeated exposure to mass media can gradually shape people's consumeristic values (Besley, 2008). While research has generally supported the cultivation effect of mass media, it deals with small changes to people over a long period of time. Such an accumulative effect cannot be empirically captured in cross-sectional data. As such, our findings, based on a survey study, cannot be conclusive.

The measure of materialism in our study is based on Richin's definition that taps into the centrality of money and procession, the belief that money leads to happiness, and judging success based on income and possessions. Other scholars conceptualize and measure materialism differently. For example, Belk (Belk, 1985; Ger \& Belk, 1996) and colleagues examine materialism as a combination of possessiveness, non-generosity, and envy. Kasser (Kasser \& Kanner, 2004) and others consider materialism as a 
manifestation of different value priorities in that materialism place relatively high priority on extrinsic goals rather than intrinsic goals.

Our use of college students as a sample has the advantage of controlling for differences in education, age, access to television, and measurement invariance. Meanwhile, it may not provide representative estimates of societal well-being and limits the external validity of our findings.

\section{Future Study}

Our findings show a positive association between social comparison and material satisfaction in all country samples. In contrast, Sirgy et al. (1998) found a negative association between TV viewership (a proxy for social comparison) and perceived standard of living in their pooled sample collected from the U. S., Canada, Australia, Turkey, and China. However, this association was not significant in any of the specific samples (Sirgy et al., 1998, p. 134). The authors attributed the marginal statistical significance to the large number of observations in the pooled sample. Our country-specific analysis provides strong and unequivocal support for a positive association between social comparison and material satisfaction (perceived standard of living). This finding suggests a possible downward comparison people make when watching television. More empirical research that replicates this relationship in the future can help establish the effect and direction of social comparison on material satisfaction.

In the big picture, the connection between economic development, societal and individual values, and well-being is complex and multifaceted. Research comparing cross-national data shows that people in rich countries report significantly higher life satisfaction than people in poor countries (Diener \& Oishi, 2000). Ahuvia (2002, p. 25) suggests that "economic development increases subjective well-being by creating a cultural environment where individuals make choices to maximize their happiness rather than meet social obligations." From this perspective, we should expect that social norms in individualist cultures promote individual happiness to a greater extent than in collectivist cultures, where the emphasis is placed on social harmony and self-criticism.

Cultivation theory, however, suggests that, within rich nations, economic prosperity could inadvertently lead to diminished well-being by prompting materialistic values and lifestyles. Future studies of cultivation theory will need to take a developmental approach to capture the change process associated with economic development and the rise of individualism, and how those changes affect people's satisfaction with life. It would be fruitful to conduct such studies at both individual and national levels. 


\section{REFERENCES}

Ahuvia, A. (2002). Individualism/collectivism and cultures of happiness: A theoretical conjecture on the relationship between consumption, culture and subjective well-being at the national level. Journal of Happiness Studies, 3(1), 23-36.

Ahuvia, A. (2008a). If money doesn't make us happy, why do we act as if it does? Journal of Economic Psychology, 29(4), 491-507.

Ahuvia, A. (2008b). Wealth, consumption and happiness. The Cambridge handbook of psychology and economic behaviour, 199-226.

Anderson, J. C., \& Gerbing, D. W. (1988). Structural equation modeling in practice: A review and recommended two-step approach. Psychological Bulletin, 103(3), 411-423.

Arnould, E. J., \& Thompson, C. J. (2005). Consumer culture theory (CCT): Twenty years of research. Journal of Consumer Research, 31(4), 868-882.

Baumeister, R. F. (1991). Meanings of life. Guilford Press.

Belk, R. W. (1985). Materialism: Trait aspects of living in the material world. Journal of Consumer Research, 12(3), 265-280.

Belk, R. W., \& Bryce, W. J. (1986). Materialism and individual determinism in US and Japanese print and television advertising. ACR North American Advances.

Besley, J. C. (2008). Media use and human values. Journalism \& Mass Communication Quarterly, 85(2), 311-330.

Burroughs, J. E., \& Rindfleisch, A. (2002). Materialism and well-being: A conflicting values perspective. Journal of Consumer Research, 29(3), 348-370.

Campbell, C. (1987). The romantic ethic and the spirit of modern consumerism. Springer.

Chan, K., \& Prendergast, G. P. (2008). Social comparison, imitation of celebrity models and materialism among Chinese youth. International Journal of Advertising, 27(5), 799-826.

Chung, T., \& Mallery, P. (1999). Social comparison, individualism-collectivism, and self-esteem in China and the United States. Current Psychology: A Journal for Diverse Perspectives on Diverse Psychological Issues, 18(4), 340-352.

Corneo, G. (2005). Work and television. European Journal of Political Economy, 21(1), 99-113.

Dawson, S., \& Bamossy, G. (1991). If “we are what we have," what are we when we don't have? An exploratory study of materialism among expatriate Americans. Journal of Social Behavior and Personality, 6(6), 363.

De Mooij, M., \& Hofstede, G. (2002). Convergence and divergence in consumer behavior: Implications for international retailing. Journal of Retailing, 78(1), 61-69.

Diener, E., Lucas, R. E., \& Oishi, S. (2002). Subjective well-being: The science of happiness and life satisfaction. Handbook of Positive Psychology, 2, 63-73.

Diener, E., \& Oishi, S. (2000). Money and happiness: Income and subjective well-being across nations. Culture and Subjective Well-being, 185-218.

Douglas, S. P., \& Craig, C. S. (2006). On improving the conceptual foundations of international marketing research. Journal of International Marketing, 14(1), 1-22.

Draganska, M., Hartmann, W. R., \& Stanglein, G. (2013). Internet versus television advertising: A brandbuilding comparison. Journal of Marketing Research, 50(5), 578-590.

Easterlin, R. A. (1995). Will raising the incomes of all increase the happiness of all? Journal of Economic Behavior \& Organization, 27(1), 35-47.

Fernandez, R. M., \& Kulik, J. C. (1981). A multilevel model of life satisfaction: Effects of individual characteristics and neighborhood composition. American Sociological Review, 840-850.

Festinger, L. (1954). A theory of social comparison processes. Human Relations, 7(2), 117-140.

Fornell, C., \& Larcker, D. F. (1981). Evaluating structural equation models with unobservable variables and measurement error. Journal of Marketing Research, 39-50.

Ger, G., \& Belk, R. W. (1996). Cross-cultural differences in materialism. Journal of Economic Psychology, 17(1), 55-77. 
Gerbing, D. W., \& Anderson, J. C. (1988). An updated paradigm for scale development incorporating unidimensionality and its assessment. Journal of Marketing Research, 186-192.

Gerbner, G., Gross, L., Morgan, M., Signorielli, N., \& Shanahan, J. (2002). Growing up with television: Cultivation processes. Media effects (pp. 53-78), Routledge.

Hamelink, C. J. (1983). Cultural autonomy in global communications: Planning national information policy.

Hine, T. (2002). I want that! How we all became shoppers. HarperCollins Publishers.

Hirschman, E. C. (1991). Presidential Address Secular Mortality and the Dark Side of Consumer Behavior: Or How Semiotics Saved My Life. ACR North American Advances.

Hofstede, G. (2003). Culture's consequences: Comparing values, behaviors, institutions and organizations across nations. Sage publications.

Huntington, S. P. (2000). The clash of civilizations? Culture and Politics (pp. 99-118). Springer.

Inglehart, R. (2006). Mapping global values. Comparative Sociology, 5(2-3), 115-136.

James, L. R., Mulaik, S. A., \& Brett, J. M. (2006). A tale of two methods. Organizational Research Methods, 9(2), 233-244.

Kasser, T. E., \& Kanner, A. D. (2004). Psychology and consumer culture: The struggle for a good life in a materialistic world. American Psychological Association.

Kline, R. B. (2015). Principles and practice of structural equation modeling. Guilford publications.

Knight, J., Song, L., \& Gunatilaka, R. (2009). Subjective well-being and its determinants in rural China. China Economic Review, 20(4), 635-649.

Krueger, A. B., Kahneman, D., Fischler, C., Schkade, D., Schwarz, N., \& Stone, A. A. (2009). Time use and subjective well-being in France and the US. Social Indicators Research, 93(1), 7-18.

Kubey, R., \& Csikszentmihalyi, M. (1990). Television as escape: Subjective experience before an evening of heavy viewing. Communication Reports, 3(2), 92-100.

Kubey, R., \& Csikszentmihalyi, M. (2002). Television addiction is no mere metaphor. Scientific American, 286(2), 74-80.

Kubey, R., \& Csikszentmihalyi, M. (2004). Television addiction. Scientific American Mind, 14(1), 48-55.

Layard, R. (2006). Happiness and public policy: A challenge to the profession. The Economic Journal, 116(510), C24-C33.

Leelanuithanit, O., Day, R., \& Walters, R. (1991). Investigating the relationship between marketing and overall satisfaction with life in a developing country. Journal of Macromarketing, 11(1), 3-23.

Levitt, T. (1993). The globalization of markets. Readings in international business: A decision approach, 249.

Lichter, R. S., Lichter, L. S., \& Rothman, S. (1994). Prime time: How TV portrays American culture. Regnery Publishing.

Markus, H. R., \& Kitayama, S. (1991). Culture and the self: Implications for cognition, emotion, and motivation. Psychological Review, 98(2), 224.

Meadow, H. L., Mentzer, J. T., Rahtz, D. R., \& Sirgy, M. J. (1992). A life satisfaction measure based on judgment theory. Social Indicators Research, 26(1), 23-59.

Melendez, N. (1987). Leisure and consumption: The influence of television commercials. World Leisure \& Recreation, 29(3), 7-11.

Mullen, M. R. (1995). Diagnosing measurement equivalence in cross-national research. Journal of International Business Studies, 26(3), 573-596.

Nieboer, A., Lindenberg, S., Boomsma, A., \& Bruggen, A. C. V. (2005). Dimensions of well-being and their measurement: The SPF-IL scale. Social Indicators Research, 73(3), 313-353.

O'Guinn, T. C., \& Shrum, L. J. (1997). The role of television in the construction of consumer reality. Journal of Consumer Research, 23(4), 278-294.

O'Leary-Kelly, S. W., \& Vokurka, R. J. (1998). The empirical assessment of construct validity. Journal of Operations Management, 16(4), 387-405.

Pollay, R. W. (1986a). The distorted mirror: Reflections on the unintended consequences of advertising. Journal of Marketing, 50(2), 18-36. 
Pollay, R. W. (1986b). Quality of life in the padded sell: Common criticisms of advertising's cultural character and international public policies. Current Issues and Research in Advertising, 9(1-2), 173-250.

Preacher, K. J., \& Hayes, A. F. (2008). Asymptotic and resampling strategies for assessing and comparing indirect effects in multiple mediator models. Behavior Research Methods, 40(3), 879-891.

Richins, M. L. (1987). Media, materialism, and human happiness. ACR North American Advances.

Richins, M. L. (1991). Social comparison and the idealized images of advertising. Journal of Consumer Research, 18(1), 71-83.

Richins, M. L., \& Dawson, S. (1992). A consumer values orientation for materialism and its measurement: Scale development and validation. Journal of Consumer Research, 19(3), 303-316.

Roberts, J. A., Manolis, C., \& Tanner, J. F., Jr. (2003). Family structure, materialism, and compulsive buying: A reinquiry and extension. Journal of the Academy of Marketing Science, 31(3), 300-311.

Rungtusanatham, M., Miller, J., \& Boyer, K. (2014). Theorizing, testing, and concluding for mediation in SCM research: Tutorial and procedural recommendations. Journal of Operations Management, 32(3), 99-113.

Rungtusanatham, M., Ng, C., Zhao, X., \& Lee, T. (2008). Pooling data across transparently different groups of key informants: Measurement equivalence and survey research. Decision Sciences, 39(1), 115-145.

Shrum, L., Burroughs, J. E., \& Rindfleisch, A. (2005). Television's cultivation of material values. Journal of Consumer Research, 32(3), 473-479.

Sirgy, M. J. (1998). Materialism and quality of life. Social Indicators Research, 43(3), 227-260.

Sirgy, M. J., Gurel-Atay, E., Webb, D., Cicic, M., Husic, M., Ekici, A., . . Johar, J. (2012). Linking advertising, materialism, and life satisfaction. Social Indicators Research, 107(1), 79-101.

Sirgy, M. J., Lee, D.-J., Kosenko, R., Lee Meadow, H., Rahtz, D., Cicic, M., . . Wright, N. (1998). Does television viewership play a role in the perception of quality of life? Journal of Advertising, $27(1), 125-142$.

Slater, D., \& Tonkiss, F. (2013). Market society: Markets and modern social theory. John Wiley \& Sons.

Speck, S. K. S., \& Roy, A. (2008). The interrelationships between television viewing, values and perceived well-being: A global perspective. Journal of International Business Studies, 39(7), 1197-1219.

Tiggemann, M., \& Polivy, J. (2010). Upward and downward: Social comparison processing of thin idealized media images. Psychology of Women Quarterly, 34(3), 356-364.

Tomlinson, J. (1999). Globalization and culture. University of Chicago Press.

Tov, W., \& Au, E. (2013). Comparing well-being across nations: Conceptual and empirical issues. Oxford Handbook of Happiness, Edited by Ilona Boniwell, Susan A. David, and Amanda Conley Ayers.

World Bank. 2014. The World Bank Annual Report 2014. Washington, DC.

Yoon, K. (1995). Comparison of beliefs about advertising, attitude toward advertising, and materialism held by African Americans and Caucasians. Psychological Reports, 77(2), 455-466.

Zhao, X., Lynch, J. G., Jr., \& Chen, Q. (2010). Reconsidering Baron and Kenny: Myths and truths about mediation analysis. Journal of Consumer Research, 37(2), 197-206. 


\section{APPENDIX A \\ SURVEY INSTRUMENT}

Social Comparison via Television Programming ( $1=$ Never to $7=$ Always $)$

SC1: When I see actors in television programs, I think about how well or how badly I dress compared to the actors.

SC2: When I see actors in television programs, I think about how I look compared to the actors.

SC3: Television programs tell me about fashion and about what to buy to impress others.

SC4: I have wished that I looked more like the actors in television programs.

SC5: Television programs help me know which products will or will not reflect the sort of person I am.

SC6: When buying clothes, I look at television programs to give me ideas about how I should look.

SC7: When buying personal care/cosmetic items, I look at television programs to give me ideas about how I should look.

Materialism

MAT1: How do you feel about acquiring material possessions as an achievement in life? $(1=$ Not important, 7 = Very important)

MAT2: Would your life be any better if you owned certain things that you don't have? $(1=$ Not any better, 7 = Much better)

MAT3: How would you feel if you could afford to buy more things? $(1=$ Not any happier, $7=$ Much happier)

Material Satisfaction $(1=$ Strongly disagree to $5=$ Strongly agree $)$

MS1: I am better off financially than most people shown on television commercials.

MS2: I am better off financially than most people shown on television programs.

MS3: I usually find that I am materially better off than the typical family shown on television programs.

MS4: I usually find that I am materially better off than the typical family in television ads.

Life Satisfaction $(1=$ Very dissatisfied, $5=$ Very satisfied $)$

LS1: Compared to your lifetime goals, ideals, and what you had ideally hoped to become, how satisfied are you?

LS2: Compared to the accomplishments of your friends and associates, how satisfied are you?

LS3: Compared to the accomplishments of most people in your position, how satisfied are you?

LS4: Compared to what you may have predicted about yourself becoming, how satisfied are you?

LS5: Compared to what you feel you should have accomplished so far, how satisfied are you?

Control Variables:

TV Viewership $(1=$ Strongly disagree and $5=$ Strongly agree $)$

TV1: I often watch television on weekends.

TV2: I spend time watching television almost every day.

TV3: I hardly ever watch television. (R)

Family Income

- More than the average family in my country

- Same as an average family in my country

- Less than the average family in my country

Gender

- Male - Female 


\section{APPENDIX B \\ SEM RESULTS FOR POOLED SAMPLE AND EACH COUNTRY}

\begin{tabular}{|c|c|c|c|c|c|c|c|c|}
\hline Structural Path & Hyp & Effect & SE & t-value & p-value & $\mathbf{U C L}$ & LCL & Result \\
\hline $\mathrm{SC} \rightarrow \mathrm{MAT}$ & $\overline{\mathrm{H} 1 \mathrm{a}}$ & .41 & .021 & 13.28 & .001 & & & Supported \\
\hline $\mathrm{SC} \rightarrow \mathrm{MS}$ & $\mathrm{H} 1 \mathrm{~b}$ & .40 & .018 & 11.70 & .003 & & & Supported \\
\hline $\mathrm{SC} \rightarrow \mathrm{LS}$ & H1c & -.22 & .022 & -5.90 & .002 & & & Supported \\
\hline $\mathrm{MAT} \rightarrow \mathrm{MS}$ & $\mathrm{H} 2 \mathrm{a}$ & -.24 & .026 & -7.09 & .003 & & & Supported \\
\hline $\mathrm{MAT} \rightarrow \mathrm{LS}$ & $\mathrm{H} 2 \mathrm{~b}$ & -.16 & .031 & -4.47 & .002 & & & Supported \\
\hline $\mathrm{MS} \rightarrow \mathrm{LS}$ & H3 & .28 & .039 & 8.42 & .003 & & & Supported \\
\hline $\mathrm{SC} \rightarrow \mathrm{MAT} \rightarrow \mathrm{MS}$ & $\mathrm{H} 4 \mathrm{a}$ & -.099 & .017 & - & .001 & -.067 & -.136 & Complementary \\
\hline $\mathrm{SC} \rightarrow \mathrm{MAT} \rightarrow \mathrm{LS}$ & $\mathrm{H} 4 \mathrm{~b}$ & -.092 & .016 & - & .002 & -.061 & -.125 & Complementary \\
\hline $\mathrm{SC} \rightarrow \mathrm{MS} \rightarrow \mathrm{LS}$ & $\mathrm{H} 5$ & .021 & .025 & - & .416 & .072 & -.026 & No mediation* \\
\hline
\end{tabular}

Appendix B (2): China $(\mathbf{N}=\mathbf{3 0 8})$
\begin{tabular}{|l|l|l|l|l|l|l|l|l|}
\hline Structural Path & Hyp & Effect & SE & $\underline{\text { t-value }}$ & p-value & $\underline{\text { UCL }}$ & $\underline{\text { LCL }}$ & Result \\
\hline $\mathrm{SC} \rightarrow \mathrm{MAT}$ & H1a & .25 & .039 & 4.44 & .002 & & & Supported \\
\hline $\mathrm{SC} \rightarrow \mathrm{MS}$ & $\mathrm{H} 1 \mathrm{~b}$ & .46 & .027 & 8.84 & .002 & & & Supported \\
\hline $\mathrm{SC} \rightarrow \mathrm{LS}$ & $\mathrm{H} 1 \mathrm{c}$ & .05 & .033 & .793 & .455 & & & Not supported \\
\hline $\mathrm{MAT} \rightarrow \mathrm{MS}$ & $\mathrm{H} 2 \mathrm{a}$ & -.28 & .039 & -5.34 & .003 & & & Supported \\
\hline $\mathrm{MAT} \rightarrow \mathrm{LS}$ & $\mathrm{H} 2 \mathrm{~b}$ & .03 & .044 & .549 & .601 & & & Not supported \\
\hline $\mathrm{MSF} \rightarrow \mathrm{LS}$ & $\mathrm{H} 3$ & .47 & .062 & 8.18 & .003 & & & Supported \\
\hline $\mathrm{SC} \rightarrow \mathrm{MAT} \rightarrow \mathrm{MS}$ & $\mathrm{H} 4 \mathrm{a}$ & -.068 & .018 & - & .002 & -.036 & -.107 & Competitive \\
\hline $\mathrm{SC} \rightarrow \mathrm{MAT} \rightarrow \mathrm{LS}$ & $\mathrm{H} 4 \mathrm{~b}$ & -.024 & .017 & - & .105 & .008 & -.062 & No effect** \\
\hline $\mathrm{SC} \rightarrow \mathrm{MS} \rightarrow \mathrm{LS}$ & $\mathrm{H} 5$ & .19 & .046 & - & .002 & .281 & .105 & Full mediation \\
\hline
\end{tabular}

Appendix B (3): Croatia ( $N=227)$

\begin{tabular}{|l|l|l|l|l|l|l|l|l|}
\hline Structural Path & $\underline{\text { Hyp }}$ & $\underline{\text { Effect }}$ & $\underline{\mathbf{S E}}$ & $\underline{\underline{\text { t-value }}}$ & $\underline{\text { p-value }}$ & $\underline{\text { UCL }}$ & $\underline{\mathbf{L C L}}$ & Result \\
\hline $\mathrm{SC} \rightarrow \mathrm{MAT}$ & $\mathrm{H} 1 \mathrm{a}$ & .47 & .04 & 7.94 & .002 & & & Supported \\
\hline $\mathrm{SC} \rightarrow \mathrm{MS}$ & $\mathrm{H} 1 \mathrm{~b}$ & .33 & .16 & 4.63 & .003 & & & Supported \\
\hline $\mathrm{SC} \rightarrow \mathrm{LS}$ & $\mathrm{H} 1 \mathrm{c}$ & -.22 & -.12 & -3.04 & .009 & & & Supported \\
\hline $\mathrm{MAT} \rightarrow \mathrm{MS}$ & $\mathrm{H} 2 \mathrm{a}$ & -.22 & -.16 & -3.01 & .008 & & & Supported \\
\hline $\mathrm{MAT} \rightarrow \mathrm{LS}$ & $\mathrm{H} 2 \mathrm{~b}$ & -.07 & .06 & -.946 & .394 & & & Not supported \\
\hline $\mathrm{MS} \rightarrow \mathrm{LS}$ & $\mathrm{H} 3$ & .30 & .07 & 4.66 & .001 & & & Supported \\
\hline $\mathrm{SC} \rightarrow \mathrm{MAT} \rightarrow \mathrm{MS}$ & $\mathrm{H} 4 \mathrm{a}$ & -.101 & .041 & - & .006 & -.031 & -.191 & Competitive \\
\hline $\mathrm{SC} \rightarrow \mathrm{MAT} \rightarrow \mathrm{LS}$ & $\mathrm{H} 4 \mathrm{~b}$ & -.062 & .039 & - & .09 & .009 & -.15 & Complementary \\
\hline $\mathrm{SC} \rightarrow \mathrm{MS} \rightarrow \mathrm{LS}$ & $\mathrm{H} 5$ & .039 & .053 & - & .472 & .148 & -.059 & No mediation \\
\hline
\end{tabular}

\begin{tabular}{|c|c|c|c|c|c|c|c|c|}
\hline Structural Path & Hyp & Effect & $\underline{\mathrm{SE}}$ & t-value & p-value & $\underline{\mathrm{UCL}}$ & $\underline{\mathbf{L C L}}$ & Result \\
\hline $\mathrm{SC} \rightarrow \mathrm{MAT}$ & $\mathrm{H} 1 \mathrm{a}$ & .42 & .058 & 4.24 & .002 & & & Supported \\
\hline $\mathrm{SC} \rightarrow \mathrm{MS}$ & $\mathrm{H} 1 \mathrm{~b}$ & .25 & .051 & 2.14 & .03 & & & Supported \\
\hline $\mathrm{SC} \rightarrow \mathrm{LS}$ & $\mathrm{H} 1 \mathrm{c}$ & -.19 & .067 & -1.61 & .153 & & & Not supported \\
\hline MAT $\rightarrow$ MS & $\mathrm{H} 2 \mathrm{a}$ & -.07 & .085 & -.634 & .587 & & & Not supported \\
\hline $\mathrm{MAT} \rightarrow \mathrm{LS}$ & $\mathrm{H} 2 \mathrm{~b}$ & -.05 & .109 & -.408 & .688 & & & Not supported \\
\hline $\mathrm{MS} \rightarrow \mathrm{LS}$ & $\mathrm{H} 3$ & .25 & .137 & 2.36 & .036 & & & Supported \\
\hline $\mathrm{SC} \rightarrow \mathrm{MAT} \rightarrow \mathrm{MS}$ & $\mathrm{H} 4 \mathrm{a}$ & -.03 & .056 & - & .533 & .073 & -.153 & No mediation \\
\hline $\mathrm{SC} \rightarrow \mathrm{MAT} \rightarrow \mathrm{LS}$ & $\mathrm{H} 4 \mathrm{~b}$ & -.027 & .045 & - & .493 & .056 & -.127 & No effect \\
\hline $\mathrm{SC} \rightarrow \mathrm{MS} \rightarrow \mathrm{LS}$ & $\mathrm{H} 5$ & .035 & .066 & - & .596 & .173 & -.087 & No effect \\
\hline
\end{tabular}


Appendix B (5): U. S. A. ( $\mathrm{N}=260)$

\begin{tabular}{|c|c|c|c|c|c|c|c|c|}
\hline Structural Path & Hyp & $\underline{\text { Effect }}$ & $\underline{\text { SE }}$ & t-value & p-value & $\underline{\mathrm{UCL}}$ & $\underline{\mathrm{LCL}}$ & Result \\
\hline $\mathrm{SC} \rightarrow \mathrm{MAT}$ & $\mathrm{H1a}$ & .43 & .042 & 7.65 & .002 & & & Supported \\
\hline $\mathrm{SC} \rightarrow \mathrm{MS}$ & $\mathrm{H} 1 \mathrm{~b}$ & .24 & .035 & 3.58 & .003 & & & Supported \\
\hline $\mathrm{SC} \rightarrow \mathrm{LS}$ & H1c & -.18 & -.039 & -2.93 & .006 & & & Supported \\
\hline $\mathrm{MAT} \rightarrow \mathrm{MS}$ & $\mathrm{H} 2 \mathrm{a}$ & -.29 & .047 & -4.40 & .002 & & & Supported \\
\hline $\mathrm{MAT} \rightarrow \mathrm{LS}$ & $\mathrm{H} 2 \mathrm{~b}$ & -.27 & .053 & -4.41 & .002 & & & Supported \\
\hline $\mathrm{MS} \rightarrow \mathrm{LS}$ & H3 & .31 & .068 & 5.62 & .003 & & & Supported \\
\hline $\mathrm{SC} \rightarrow \mathrm{MAT} \rightarrow \mathrm{MS}$ & $\mathrm{H} 4 \mathrm{a}$ & -.125 & .032 & - & .001 & -.063 & -.195 & Competitive \\
\hline $\mathrm{SC} \rightarrow \mathrm{MAT} \rightarrow \mathrm{LS}$ & $\mathrm{H} 4 \mathrm{~b}$ & -.155 & .033 & - & .001 & -.098 & -.234 & Complementary \\
\hline $\mathrm{SC} \rightarrow \mathrm{MS} \rightarrow \mathrm{LS}$ & H5 & -.081 & .043 & - & .05 & .001 & -.169 & Complementary \\
\hline
\end{tabular}

Mediating results for hypothesis $4 \mathrm{~b} \mathrm{SC} \rightarrow \mathrm{MAT} \rightarrow \mathrm{LS}$ are based on a partial SEM model without MS. All other results are based on a full multiple-step multiple mediator SEM model.

P-Value: bootstrap approximation obtained by constructing two-sided bias-corrected confidence intervals.

Variable notation: SC - Social Comparison; MAT-Materialism; MS - Material Satisfaction; LS-Life Satisfaction Upper Bounds, Lower Bounds: an indirect mediating effect is not significant if zero falls between the upper bound and lower bound

Pooled sample model fit: $\mathrm{CMIN} / \mathrm{DF}=1.969, \mathrm{SRMR}=.043, \mathrm{CFI}=.97, \mathrm{RMSEA}=.033, \mathrm{PCLOSE}=1.0$

Multigroup model fit: $\mathrm{CMIN} / \mathrm{DF}=1.552, \mathrm{SRMR}=.068, \mathrm{CFI}=.939, \mathrm{RMSEA}=.025, \mathrm{PCLOSE}=1.0$

AMOS results report: the standardized indirect (mediated) effect of the independent variable on dependent variable means due to the indirect (mediated) effect, when the independent variable goes up by 1.0 standard deviation, the dependent variable goes up/down by $\mathrm{x}$ standard deviations. This effect is in addition to any direct (unmediated) effect that the independent variable may have on the dependent variable (Kline, 2015, p. 134).

*No effect: the direct path between the independent variable and the dependent variable is not significant, and the mediating path is not significant.

**No mediation: the direct path between the independent variable and the dependent variable is significant, but the mediating path is not significant. 